\title{
Crystal Isomers of $\mathrm{ScFeO}_{3}$
}

Yosuke Hamasaki, ${ }^{\dagger}$ Takao Shimizu, ${ }^{\ddagger}$ Shintaro Yasui $^{*}{ }^{* \dagger}$ Tomoyasu Taniyama, ${ }^{\dagger}$ Osami

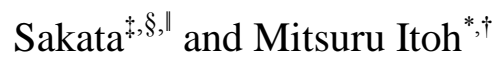

${ }^{\dagger}$ Laboratory for Materials and Structures, Institute for Innovative Research, ${ }^{\ddagger}$ Center for Elemental Research, and "Department of Materials Science and Engineering, School of Materials and Chemical Technology, Tokyo Institute of Technology, 4259, Nagatsuta, Midori-ku, Yokohama, 226-8503 Japan

${ }^{\S}$ Synchrotron X-ray Station at SPring-8, National Institute for Materials Science, 1-1-1 Kouto, Sayocho, Sayogun, Hyogo, 679-5148 Japan.

* To whom correspondence should be addressed. E-mail: itoh.m.aa@m.titech.ac.jp, and yasui.s.aa@m.titech.ac.jp 
1. XRD $\phi$-scan patterns in $\mathrm{ScFeO}_{3}$ film on $\mathrm{SrTiO}_{3}(111)$

XRD $\phi$-scan patterns were measured around $\mathrm{SrTiO}_{3}\{110\}$ and $\kappa-\mathrm{Al}_{2} \mathrm{O}_{3}$-type $\mathrm{ScFeO}_{3}\{209\}$ reflections (Figure S1).

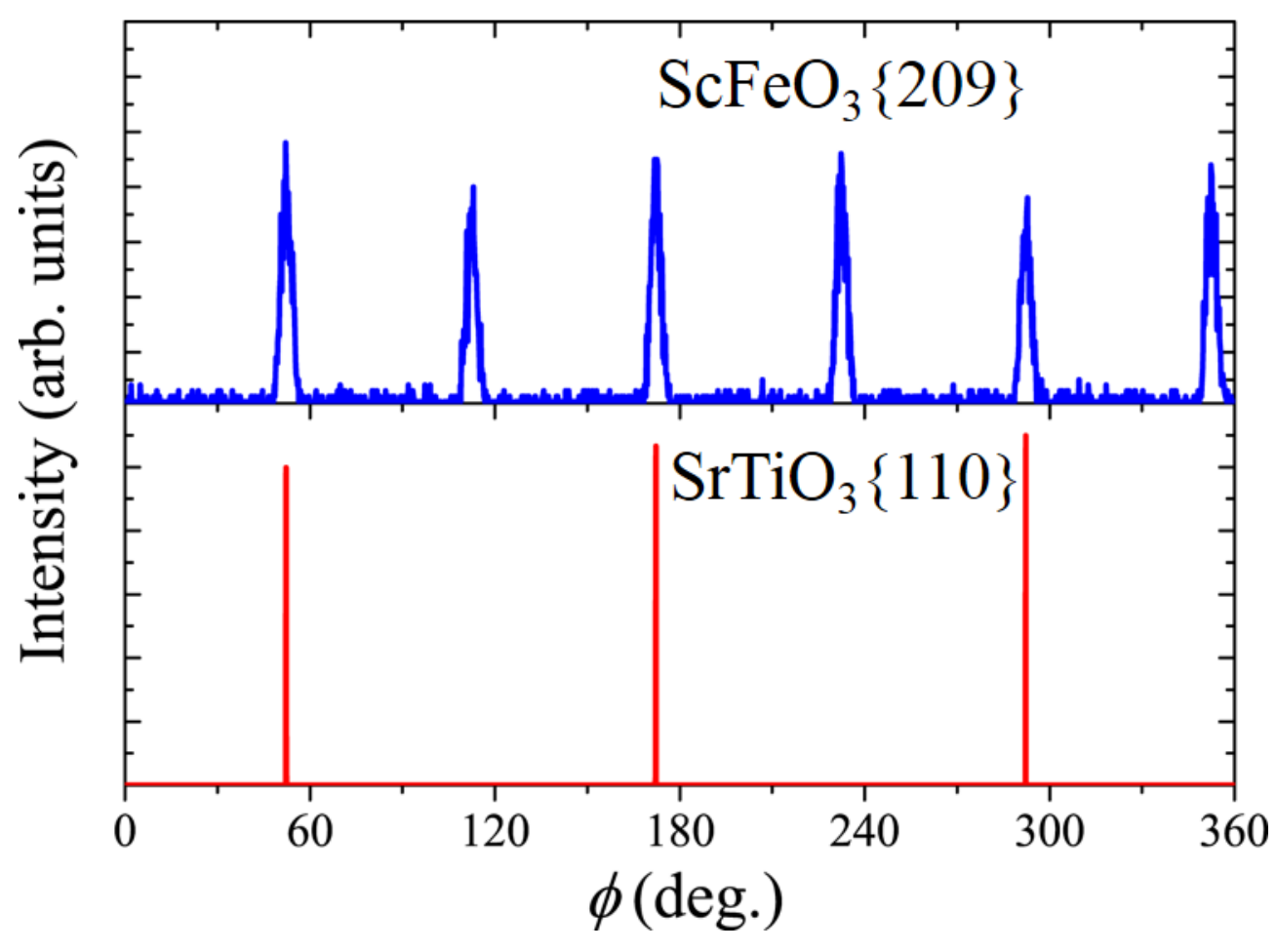

Figure S1. $\phi$-scan patterns of $\mathrm{SrTiO}_{3}\{110\}$ and $\kappa-\mathrm{Al}_{2} \mathrm{O}_{3}$-type $\mathrm{ScFeO}_{3}\{209\}$. 


\section{XRD-RSM images of $\mathrm{ScFeO}_{3}$ film on $\mathrm{MgO}(001)$}

Figure S2 shows wide-range XRD-RSM for $\mathrm{ScFeO}_{3}$ film on $\mathrm{MgO}(001)$ along $\mathrm{MgO}(001)$ [110] direction.

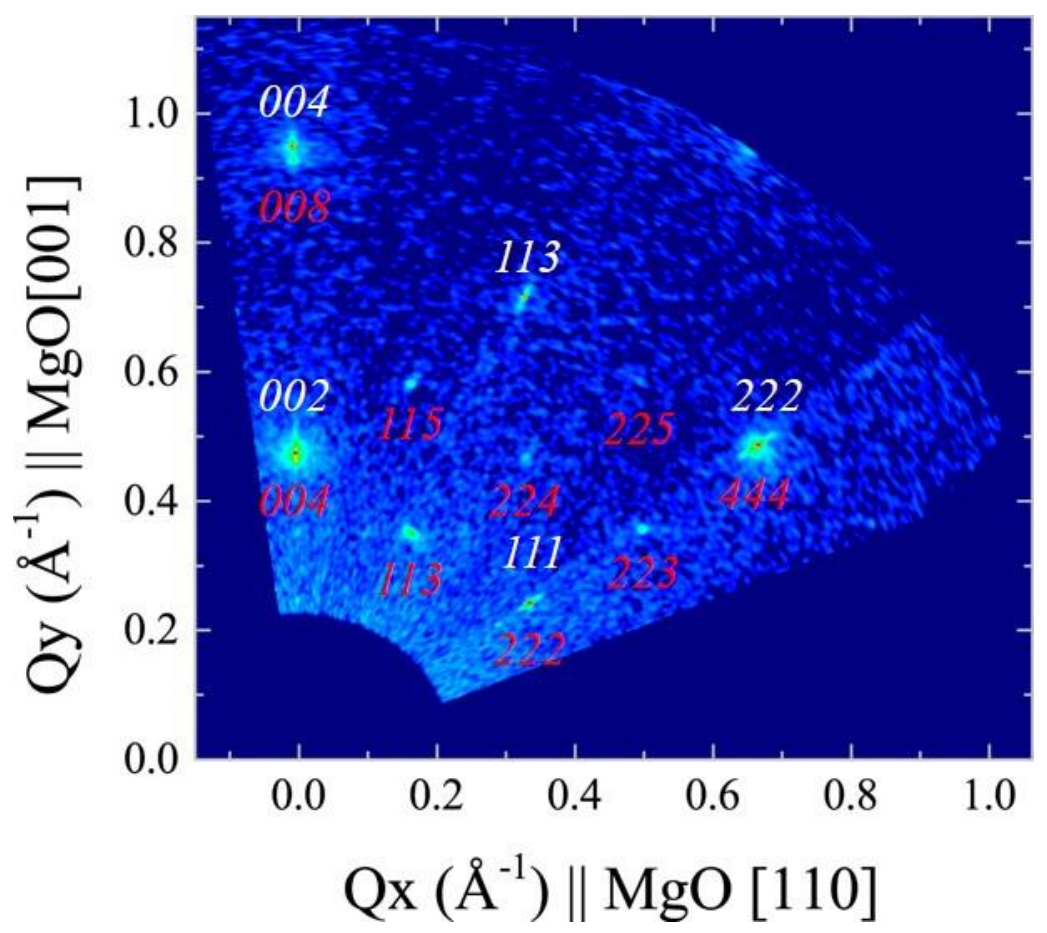

Figure S2. Wide-range XRD-RSM of $\mathrm{ScFeO}_{3}$ film on $\mathrm{MgO}(001)$ along $\mathrm{MgO}(001)$ [110]. Red and white indexes indicate $\mathrm{MgO}$ substrate and $\mathrm{ScFeO}_{3}$ film reflections, respectively. 
HRXRD-RSM image was also recorded around $\mathrm{MgO} 204$ and spinel-type $\mathrm{ScFeO}_{3} 408$.

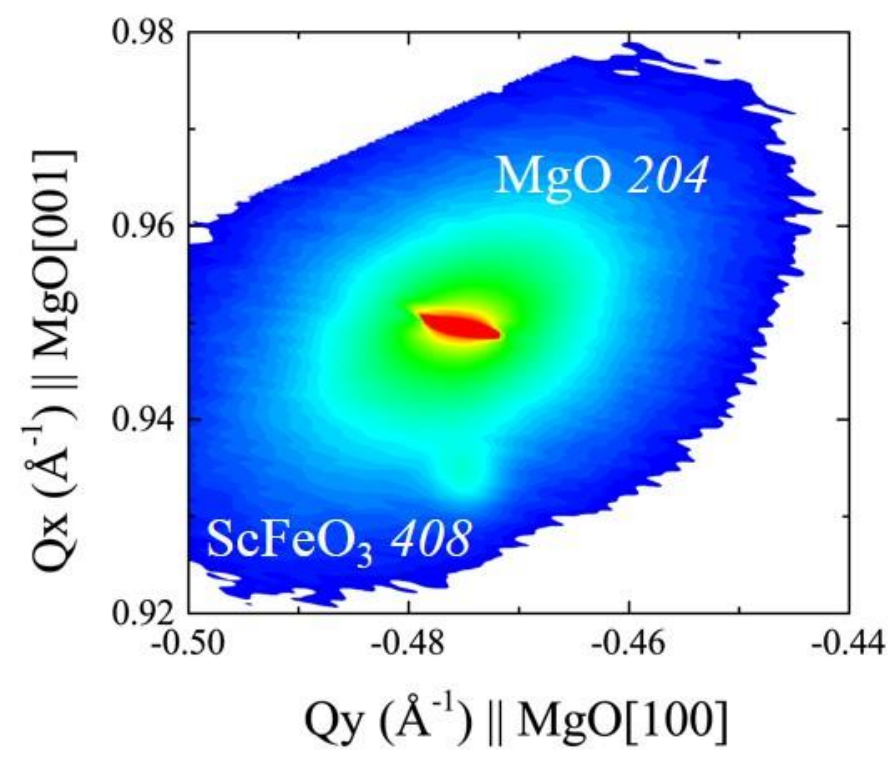

Figure S3. HRXRD-RSM image of $\mathrm{ScFeO}_{3}$ film on $\mathrm{MgO}(001)$ measured around $\mathrm{MgO} 204$ diffraction. 


\section{STEM-EDX analysis of $\mathrm{ScFeO}_{3}$ film on $\mathrm{Fe}_{2} \mathrm{O}_{3} / \mathrm{Al}_{2} \mathrm{O}_{3}(0001)$}

Figure $\mathrm{S} 4$ shows the HAADF-STEM image of $\mathrm{ScFeO}_{3}$ film on $\mathrm{Fe}_{2} \mathrm{O}_{3} / \mathrm{Al}_{2} \mathrm{O}_{3}(0001)$. We performed STEM-EDX for two spots; 1 and 2 positions. The result of STEM-EDX is summarized in Table S1.

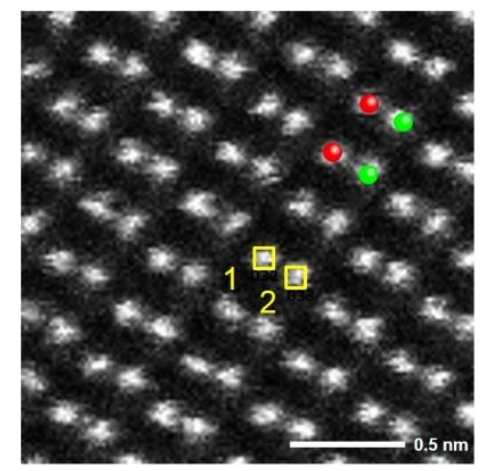

Figure S4. HAADF-STEM image of $\mathrm{ScFeO}_{3}$ film on $\mathrm{Fe}_{2} \mathrm{O}_{3} / \mathrm{Al}_{2} \mathrm{O}_{3}(0001)$. Yellow squares correspond to positions analyzed by STEM-EDX.

Table S1. The ratio of Sc and Fe at two positions.

\begin{tabular}{|c|c|c|}
\hline Position & $\operatorname{Sc}(\%)$ & $\mathbf{F e}(\%)$ \\
\hline 1 & 42 & 58 \\
\hline 2 & 43 & 57 \\
\hline
\end{tabular}


Figure S5 shows HAADF-STEM image of $\mathrm{ScFeO}_{3}$ film on $\mathrm{NdCaAlO}_{4}(001)$. We performed STEM-EDX for four spots; 1, 2, 3 and 4 positions. The result of STEM-EDX is summarized in Table S2.

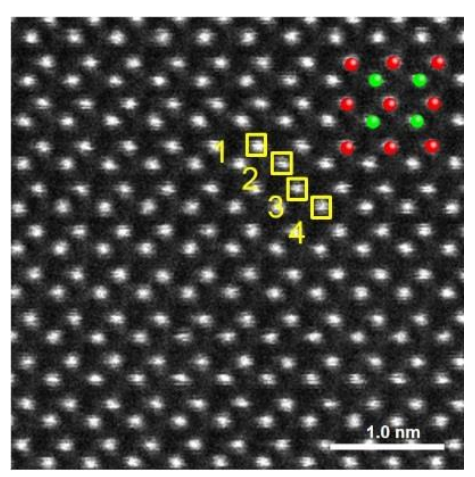

Figure S5. HAADF-STEM image of $\mathrm{ScFeO}_{3}$ film on $\mathrm{Fe}_{2} \mathrm{O}_{3} / \mathrm{NdCaAlO}_{4}(001)$. Yellow squares correspond to positions analyzed by STEM-EDX.

Table S2. The ratio of Sc and Fe at four positions

\begin{tabular}{|c|c|c|}
\hline Position & $\operatorname{Sc}(\%)$ & $\mathbf{F e}(\%)$ \\
\hline 1 & 49 & 51 \\
\hline 2 & 51 & 49 \\
\hline 3 & 52 & 48 \\
\hline 4 & 49 & 51 \\
\hline
\end{tabular}




\section{Detailed characterization of $\mathrm{YMnO}_{3}$-type $\mathrm{ScFeO}_{3}$ film by XRD measurements}

In order to investigate on in-plane relationship, we performed XRD $\phi$-scan around $\mathrm{Al}_{2} \mathrm{O}_{3}\{20-24\}$ and $\mathrm{YMnO}_{3}$-type $\mathrm{ScFeO}_{3}\{30-3 \underline{12}\}$ reflections (Figure S6).

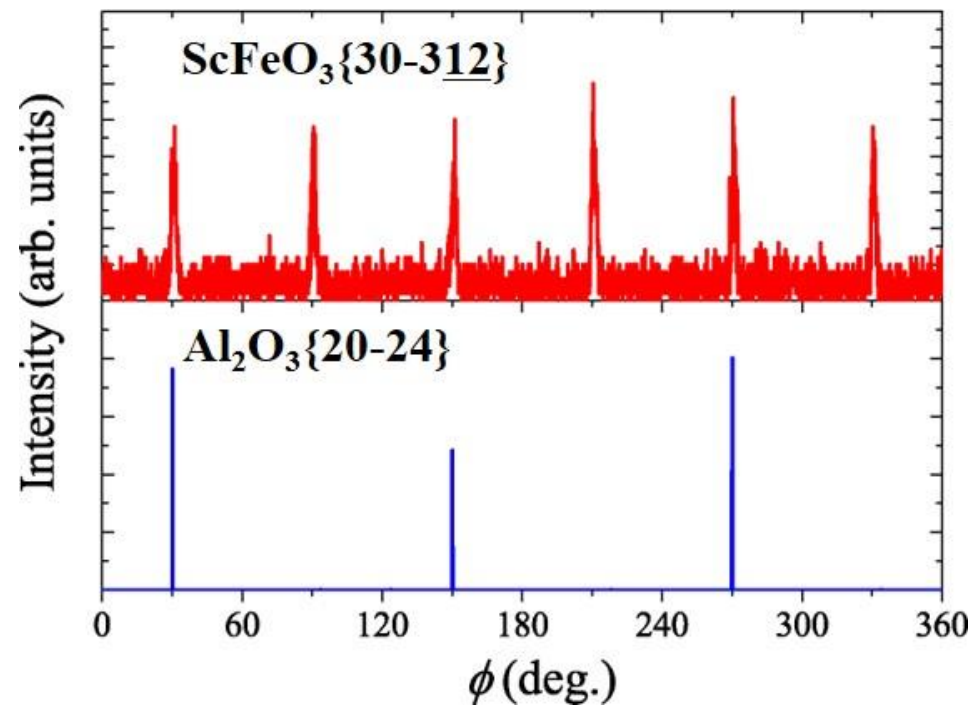

Figure S6. $\phi$-scan patterns of $\mathrm{YMnO}_{3}$-type $\mathrm{ScFeO}_{3}\{30-3 \underline{12}\}$ and $\mathrm{Al}_{2} \mathrm{O}_{3}\{20-24\}$. 
In order to distinguish between polar $\left(\mathrm{Pb}_{3} \mathrm{~cm}\right)$ and non-polar $\left(\mathrm{Pb}_{3} / \mathrm{mmc}\right)$ structures, we performed HRXRD 2 $\theta$ - $\omega$ scan along the $\mathrm{YMnO}_{3}$-type $\mathrm{ScFeO}_{3}$ [30-312] direction. (Figure S7).

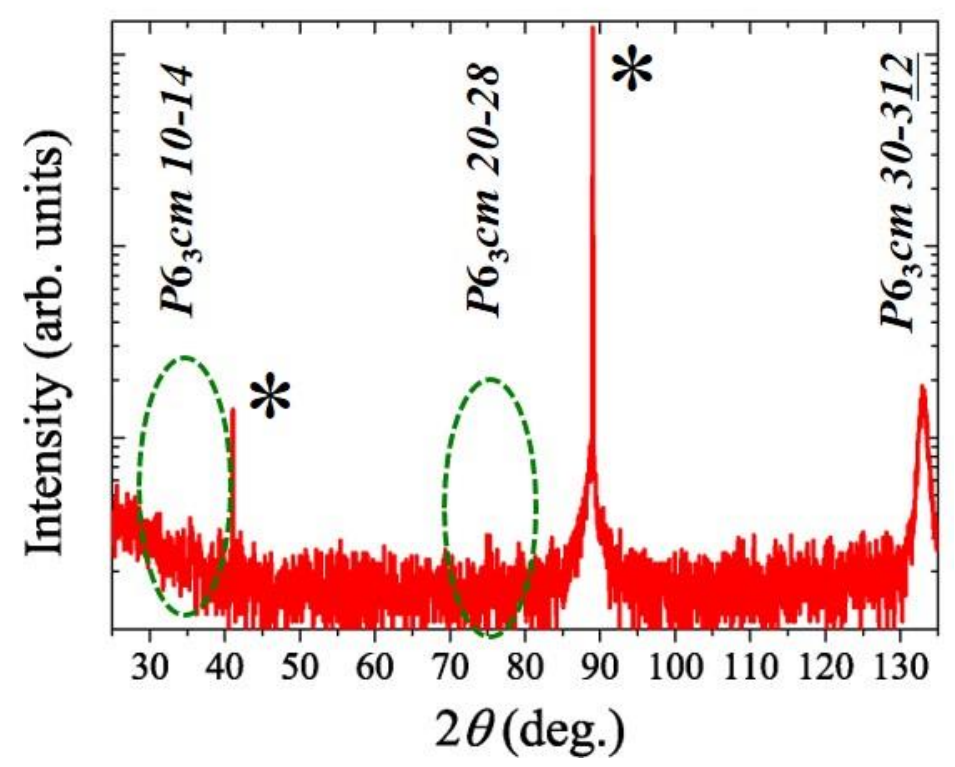

Figure S7. HRXRD $2 \theta-\omega$ pattern of $\mathrm{YMnO}_{3}$-type $\mathrm{ScFeO}_{3}$ film along $\mathrm{YMnO}_{3}$-type $\mathrm{ScFeO}_{3}$ [30-312] direction. * indicates peaks of $\mathrm{Al}_{2} \mathrm{O}_{3}$ substrate. 
Schematic illustrations of diffraction patterns of $P 6_{3} \mathrm{~cm}$ and $P 6_{3} / \mathrm{mmc}$ structures are shown in Figure S8. [10-10] direction of $P 6_{3} \mathrm{~cm}$ structure corresponds to [11-20] of $P 6_{3} / \mathrm{mmc}$ structure.
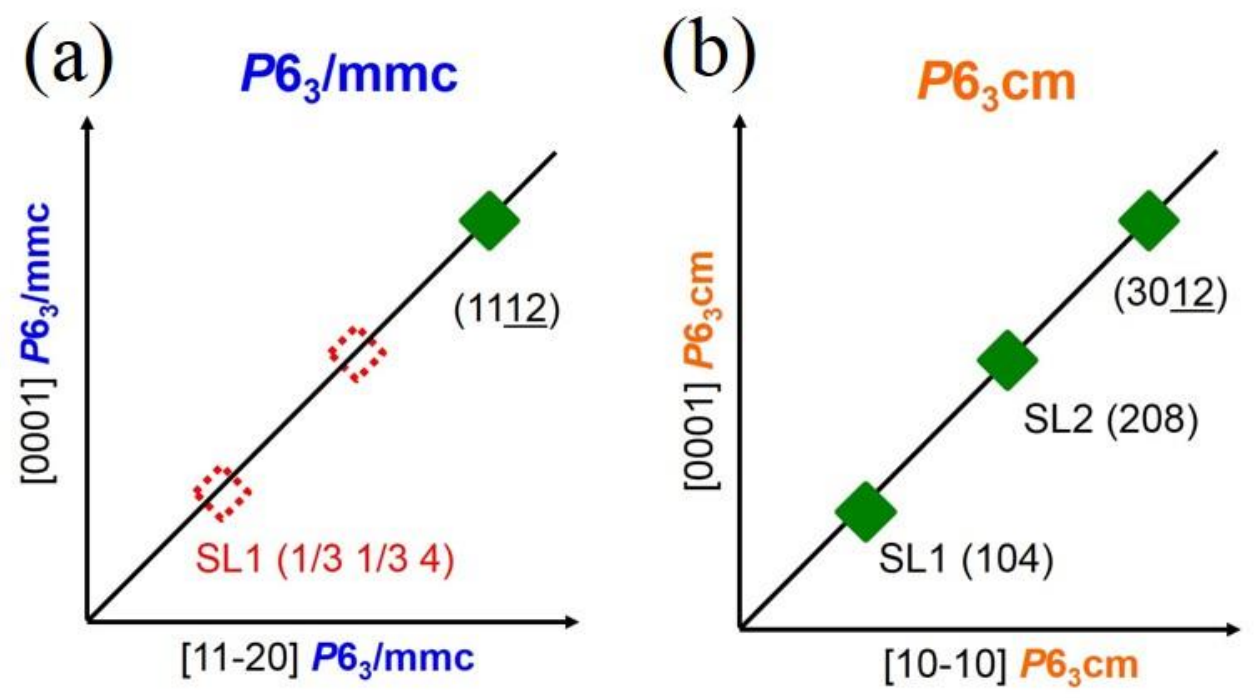

Figure S8. Schematic illustrations of the difference of diffraction patterns, (a) $P 6_{3} / m m c$ and (b) $P 6_{3} \mathrm{~cm}$. Red dots and green squares indicate forbidden and general diffractions, respectively. 
We also found different arrangement of atoms in comparison with Figure 11(b). Another view of HAADF-STEM image of $\mathrm{ScFeO}_{3}$ film on YSZ(001) along YSZ(001) [100] was displayed in Figure S9. Bright dots were aligned along horizontal direction of YSZ [010].

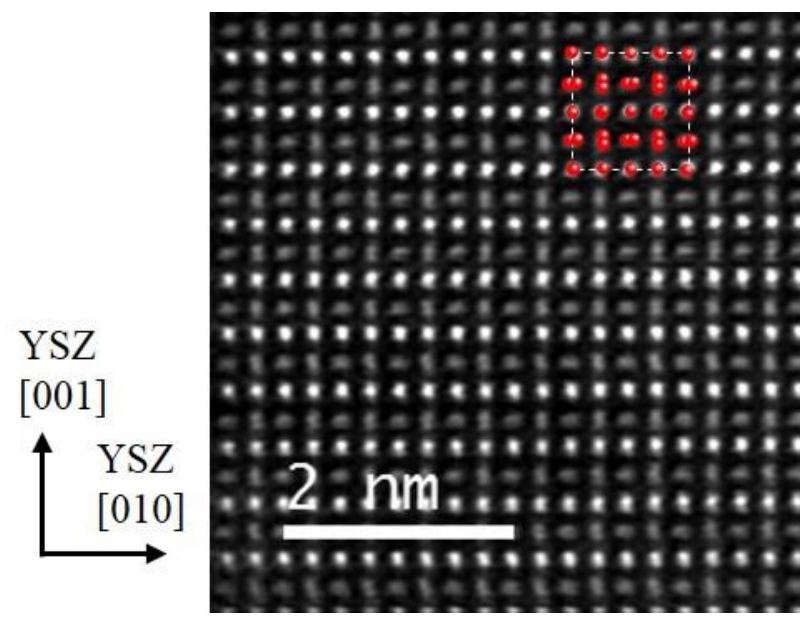

Figure S9. HAADF-STEM image of $\mathrm{ScFeO}_{3}$ film on $\mathrm{YSZ}(001)$. The direction of view is $\mathrm{YSZ}(001)$ [100]. Simulated cationic positions and the unit cell are indicated by circles and broken lines, respectively. 